\title{
THE EMOTIONAL CONTROL METAPHORS
}

\author{
CARMelo PÉrez Rull \\ I. E. S. Al-Andalus (Almería)
}

\begin{abstract}
In this paper we are concerned with the metaphors capturing the aspect of control. Emotion is conceptualized as a force inside the person that can exert pressure on him or her and the person, in turn, is seen as an entity exerting a counterforce in an attempt to control that force. The control aspect of emotion concepts is highlighted by several metaphors. The metaphorical source domains that focus on this aspect include: FLUIDS UNDER PRESSURE, OBJECTS, OPPONENTS, CAPTIVE ANIMALS, NATURAL FORCES, INSANITY, INTOXICATION, SUPERIORS, BEING ON THE GROUND, REDUCING THE TEMPERATURE. In this way we draw our attention to the metaphors converging in the stages two and three of the five-stage scenario: attempt at control and loss of control.
\end{abstract}

\section{INTRODUCTION}

Emotions originate from exposure to specific situations. Emotion terms are not pure categories that can be defined by componential analysis, by means of a minimal number of conceptual components. Componential analysis does not seem to represent the way people think and express their emotions. It is virtually impossible to talk about emotions without conceptualizing them metaphorically (Kövecses 1990, 2000).

Lakoff and Johnson (1980: 29) claim that "... most of our nonphysical reality is structured, understood, and created by metaphors..." We come to know our thoughts and feelings by analogy to the physical world. In domains where there is no clear preconceptual structure to our experience, we import 
such structure via metaphor. Metaphor provides us with a means of comprehending domains of experience that do not have a preconceptual structure of their own. Lakoff and Johnson proposed that metaphor was a basic structure of understanding through which we conceptualize one domain (the target domain which is unfamiliar or abstract) in terms of another (the source domain, most often familiar and concrete). The corresponding relationship between these domains constitutes an organised conceptual metaphor. A linguistic metaphor will be an expression of such a mapping through language. The image- schemas, that are abstract constructs, lie at the base of metaphorical expressions.

How do people control their emotions and prevent the physiological and behavioural effects from showing? How do we perceive the world around us, the feelings within us and repress what is going on inside us? In our present culture, emotions are often perceived as something to be dreaded, as though they might overwhelm us. We feel lost when emotions take over. We don't know what is going on and we have no control over what is happening (Kövecses 2000). Therefore, it is often extremely important in our present society, under certain circumstances, to repress our emotions and try to avoid the loss of emotion control.

The main task of the control metaphors is to express the standard ways of conceptualizing how we come to have our emotions under control, and how we lose control over them. Consider the following expressions: "You shouldn't cork your emotions up like that," "He was bursting with joy," "He could not conceal his delight," "She is ruled by her emotions," "She hid her face in the pillow to stifle her sobs," "She could not dam back her tears," "He has cooled down a bit," "I'm on cloud nine," "She drove him berserk," "His feelings of happiness broke loose," "She's been wrestling with her feelings," "The girl couldn't hold back her tears of joy," "He was beside himself with joy"

All these linguistic expressions belong to the phase of attempting at control, loss of control and lack of control and they have been motivated by the following cognitive and cultural models (Lakoff 1987, 1999; Köveces 1986,2000):

1. THE BODY IS A CONTAINER FOR THE EMOTIONS

2. EMOTIONS ARE FORCES

3. EMOTIONS ARE FLUIDS UNDER PRESSURE IN A CONTAINER

4. EMOTIONS ARE OBJECTS

5. EMOTIONS ARE OPPONENTS

6. EMOTIONS ARE CAPTIVE ANIMALS

7. EMOTION IS INSANITY

8. EMOTION IS INTOXICATION 


\section{EMOTIONS ARE SOCIAL SUPERIORS}

10. SELF-CONTROL IS BEING ON THE GROUND

11. TO HAVE OUR EMOTIONS UNDER CONTROL IS TO KEEP A COMPLETE OBJECT TOGETHER.

The linguistic examples provided in this paper have been extracted from lexicographical sources, magazines, newspapers, fiction, informants, a wide variety of papers written by Lakoff (1993: 1999), Kövecses (1986, 2000) and from the following web page: Metaphor Home Page (hyperlink "http:// cogsci.berkeley.edu").

In this paper we are concerned with the prototypical mental models underlying the convenzionalized linguistic expressions that we use to control our emotions. We won't study in detail the set of linguistic expressions of each of the general cognitive-cultural models presented. Only at the end of this work we provide an integrated semantic description of an emotive expression by unpacking the different types of meaning representation.

In the following section, we attempt a cognitive-cultural characterization of some of these models.

\subsection{THE COGNITIVE MODEL: EMOTIONS ARE FORCES}

The self is commonly thought of as a space or container where internal events such as thoughts, beliefs and emotions, etc., are generated. Emotions can be conceptualized as internal forces moving inside people exerting some pressure from the inside. On the other hand, the external events affecting the self are seen as external forces. These forces are conceptualized as moving objects or substances that can exert a force on us and help us move to our destination or impede our movement to achieve our goals: "Things are going with me," "Things are going against me". The objects can also be manifested as fluids: "I'm trying to keep my head over water," "We're all in the same boat," or, as animals that can run away or break loose: "Try to keep a tight rein on the situation," "Keep a grip on the situation," "Don't let things get out of hand," (Lakoff 1999: 192)

The internal forces that may destabilize the person are commonly conceived of metaphorically as a fluid, air, something solid, an animal, an enemy or a force of nature. In order not to lose our balance and remain upright, in control over emotions, one must be strong enough to stand up to them. Below we present some linguistic expressions that show that cognitively and linguistically emotions are represented as this kind of force:

FLUID: She was overflowing with love

AIR: He was breathing fire 
SOMETHING SOLID: He had a lump in his throat

ANIMAL: He has a fierce temper

ENEMY: She fought back the impulse to laugh

FORCE OF NATURE: Waves of passion came over him.

\subsection{EMOTION SCENARIO}

Kövecses (1990, 2000) suggested that the folk theory of emotions can be characterized as a five-stage scenario, or cognitive model, as shown below:

Cause $\rightarrow$ Emotion $\rightarrow$ Control $\rightarrow$ Loss of Control $\rightarrow$ Behavioral Response.

There seems to exist a convincing scenario for negative emotions. Lakoff and Kövecses (1987) provide a prototypical cognitive model for anger:

1. Internal or external stimulus that causes the emotion to come into existence

2. The emotion exists. The emotion exerts force on the Self and the Self experiences physiological effects: pressure, agitation, etc.

3. Attempt to control emotion. Self exerts a counterforce in an attempt to control emotion

4. Loss of control. The intensity of emotion goes above the limit and the emotion takes control of the Self. Self exhibits behaviour.

5. Retribution. The intensity of emotion drops to zero and the emotion ceases to exist.

Our task is to uncover the metaphors converging on stages three and four: attempting to control emotion and loss of emotion control. The aspect of control is one of the set of aspects such as existence, intensity, passivity, evaluation that characterize emotion concepts (Kövecses 2000: 43). Here we are interested in how the control component of the scenario is metaphorically conceptualized. If emotions are conceptualized as forces, then the general metaphors related to the stage of control are:

1. ATTEMPT AT CONTROL IS STRUGGLE WITH FORCE

2. LOSS OF CONTROL IS LOSS OF CONTROL OVER FORCE

3. LACK OF CONTROL IS LACK OF CONTROL OVER FORCE

The metaphorical source domains used in the understanding of the control aspect of emotions are: CONTAINER, NATURAL FORCE, CAPTIVE ANIMAL, OPPONENT, INSANITY, SOCIAL SUPERIOR, UP/DOWN DIMENSION, IN/OUT DIMENSION, TEMPERATURE. 
The four general cognitive models and the special cases of every model that we are going to deal with in order to study the aspect of control are:

1. THE CONTAINER MODEL

1.1. EMOTIONS ARE FLUIDS UNDER PRESSURE

1.2. SELF-CONTROL IS BEING INSIDE THE CONTAINER

1.3. EMOTIONS ARE OBJECTS

2. THE BOUNDED REGION MODEL

2.1 EMOTIONS ARE WILD ANIMALS

2.2. EMOTIONS ARE OPPONENTS

2.3. EMOTIONS ARE NATURAL FORCES

3 VERTICAL MODEL

3.1 EMOTIONS ARE SOCIAL SUPERIORS

3.2 SELF-CONTROL IS BEING ON THE GROUND

4 THE TEMPERATURE MODEL

4.1. REDUCING EMOTIONAL INTENSITY IS REDUCING TEMPERATURE.

\section{ANALYSIS OF THE MODELS}

\subsection{THE CONTAINER MODEL}

English culture seems to conceive human beings as containers and emotions as a kind of substance inside the container. We have many expressions that conceptualize people as full of feelings of all kinds which may well up, bubble up, and overflow: "He was brimming with satisfaction"; or, otherwise, control takes place when the emotions are contained or kept down inside the container: "He kept his anger bottled up inside him". The container may be affected by external events that are seen as external forces. Hence, the emotional cause is seen as a blow that may immobilize or freeze the contents of the container: "My blood froze when I saw it". The blow may also destabilize, touch, penetrate, pierce, cut, sting, etc., the container: "Her misery pierced his heart". If the consequences of the blow are more lasting and serious the container can be crushed, broken or shattered: "She broke down and wept".

\subsubsection{EMOTIONS ARE FLUIDS UNDER PRESSURE IN A CONTAINER}

The CONTAINER metaphor captures not only the intensity aspect of the emotion but also the aspect of control. The conceptual metaphor that we activate in our minds when we wish to control our emotional states and that seems to be the central one for the elaboration of the aspect of control is 
EMOTIONS ARE ENTITIES UNDER PRESSURE IN A CONTAINER. The body is the container for emotions where a number of internal processes, that needs to be hidden and repressed, takes place. This can be seen in everyday linguistic examples where the emotions are conceptualized as entities that try to move from inside to outside the container exerting pressure on the person that in turn exerts a counterforce over those entities in an attempt to control and keep them down. In the example "He repressed his laugh", the force and counterforce schema interact within the container. Peña (1998) points out that: "There are two force vectors which move along a path or are within a container and they collide face-to-face because both of them, the emotion and the subject, want to control the situation". Johnson (1987: 46) defines the counterforce as "two equally strong, nasty, and determined force centers collide face-to-face, with the result that neither can go anywhere".

Emotions can also act as the force of a fluid. By experience we know that the level of a fluid may go up inside the container and overflow it under pressure. The fluid with pressure corresponds to the emotion and the pressure on the container corresponds to the emotion forcing the person to respond. The attempt to keep the substance inside is the attempt of the person to control the emotion: "I just kept all that junk bottled up inside me". If the person is unable to keep the substance inside the container, two things may happen: a) the explosion or b) the overflowing of the container. This entails an uncontrolled violent response or an uncontrolled nonviolent response. Mild emotions such as affection and sadness are conceptualized as overflowing the container: "His eyes were overflowing with emotion," whereas the explosion of the container is expressed with stronger emotions: "He exploded with laughter" (Kövecses 2000: 67). The explosion of the container can harm the person affected by the emotion; therefore it is psychologically advisable not to repress emotions to the point that the container explodes: "It is very bad for you to cork up your emotions like that".

\subsubsection{SELF-CONTROL IS BEING INSIDE THE CONTAINER}

As we have seen, the control of Self over emotions is conceptualized as being located inside the container: SELF-CONTROL IS BEING INSIDE THE CONTAINER. The person is out of control when the entities are out of the container where they normally reside. The sentences "A few months after the trial, he finally cracked" and "He burst out crying" are examples of the cognitive model THE LOSS OF EMOTIONAL CONTROL IS THE EXPLOSION OF THE CONTAINER. As a result of the explosion, what is inside comes out: "He lay there, flooded with pain, fear and hatred," "She was overflooding with love". When the entities are out of the container, it is difficult to exert any control over them. Self-control is regained when the entities are back together 
inside the container or when the pieces of the container are put back together. TO HAVE OUR EMOTIONS UNDER CONTROL IS TO KEEP A COMPLETE OBJECT TOGETHER: "Pulling herself together she managed to fight back her annoyance".

Lakoff (1999: ch 13) points out that a person is split between subject and self. The subject represents the locus of consciousness, subjective experience, reason, will, etc. The Self consists of everything else: our bodies, our social roles, etc. In a normal state of consciousness the Subject has control over the Self. This is indicated because both Subject and Self reside in the same location. According to Lakoff, maintaining that state of consciousness and that control is a major matter of our lives. The sentence "He is beside himself with joy" indicates that the person is out of his usual location. He doesn't reside inside the Self any longer and, consequently, the person has lost his control over the Self because LACK OF NORMAL CONSCIOUSNESS AND CONTROL IS BEING OUTSIDE THE SELF.

\subsubsection{EMOTIONS ARE OBJECTS}

Emotions understood as objects can undergo all sorts of manipulations and they can be concealed or kept visible. Holding on to objects and manipulating them is one of the things that we learn very early in our lives. So one way of exerting control over an object is by moving or hiding it, that is, making it invisible. We get most of our knowledge through vision: "Get it off your chest," "Pour out your heart", "You let your feelings out too much". "He could scarcely conceal his pleasure at my resignation" That is, we usually conceptualize KNOWING AS SEEING (Lakoff and Johnson 1980; Jonhson 1987; Lakoff \& Turner 1989; Sweetser 1990). On the other hand, if we don't want people to know about anything in particular we have to hide it. Thus in: "She tried to hide her feelings," "She never allowed me a glimpse of her feelings," are metaphorical expressions of the conceptual metaphor TO KEEP UNKNOWN IS TO KEEP INVISIBLE. Verbs involving unwillingness on the part of the individual to keep their emotions unknown are: Hide, conceal, hold something back, keep something back, keep something to oneself, etc.

\section{THE BOUNDED REGION MODEL}

People feel in control in their normal location or surroundings and less in control in strange places. Being out of control is viewed as being out of the place where a person normally resides. The further the distance between the subject or the emotion and the container, the less self-control such a container will have over the subject or emotion. (Lakoff 1999: 274; Peña 1998). A person is out of control when he cannot hold his emotions conceptualized as 
opponents, captive animals, etc., in the bounded space or location where they normally reside. The conceptualization of abnormal states of mind relies on spatial and orientation metaphors that are the result of the metaphorical projections: IN/OUT schema and UP/DOWN schema. Leaving or going out of the location is going out of the normality parameter into the abnormality one: "He went berserk when he heard the news". The UP/DOWN SCHEMA represents the conceptualization of positive and negative states of mind: "He is on top of the world," "He was down in the dumps" (Lakoff 1999; Kövecses 2000; Martín Morillas 2000)

\subsection{EMOTIONS ARE OPPONENTS}

Many negative emotions such as grief are metaphorically seen as opponents with which we have to struggle to maintain control over the emotion. In this metaphor (Kövecses 1990, 2000), the metaphorical expression "He was wrestling with his emotions", the FORCE and COUNTERFORCE schemas interact. Peña (1998) points out that: "There are two force vectors which move along a path or are within a container and they collide face-toface because both of them, the emotion and the subject, want to control the situation". The emotion as one opponent attempts to cause the person to give in to his force but the person tries to keep the emotion under control. The outcome of the struggle is victory or defeat: "He was seized by emotion," "She finally overcame her fear". Losing control is often conceptualized as something negative taking possession of the subject seizing it, gripping it, carrying it away, etc.: "He was in the grip of fear".

The main focus of the OPPONENT METAPHOR seems to be the attempt to keep the emotions under control. Controlling the emotion is controlling the enemy. This can take the following forms:

1. Having the enemy under control in a location "He could hardly contain his laughter"

2. Repressing the enemy "She suppressed a laugh"

3. Fighting the enemy "He's wrestling with his anger"

4. Treating the enemy cruelly "He smothered his feelings"

\subsection{EMOTIONS ARE CAPTIVE ANIMALS}

The fact that we have to keep emotions under control is based on the conceptualization of emotions as wild ANIMALS that try to get away from a 
location exerting some force on the person. On the other hand, the person undergoing the emotion is trying to maintain emotional control by holding the animal back: "He couldn't hold back his tears of joy," "He kept his emotions in check".

Animals at large can harm us. So they must be kept in captivity. Loss of control is equivalent to the animal getting loose: "He lost his grip on his anger," "His feelings of happiness broke loose," "He unleased his emotions," "She let go of her feelings". The behaviour of a person who has lost control is the behaviour of a wild animal: "He began to bare his teeth," "He started snarling".

\subsection{EMOTIONS ARE NATURAL/PHYSICAL FORCES}

Natural phenomena like storms, floods or wind seem to be present in the conceptualization of emotions to express passivity and lack of control (Kövecses 2000: 71). Emotions can be conceptualized metaphorically as natural agents exerting a great force on the person affected by the emotion. The emotion can come over an individual, sweep him off, bowl him over, knock him off, engulf him etc. These verbs of motion indicate the emotional response that the self undergoes. The following linguistic expressions are examples of this metaphor: "She swept me off my feet," "She was carried away by love." The person who is carried away by the uncontrollable force of nature has a passive role with no control over the situation and as result he can't help being transported from one location to another. The COMPULSION schema provides the basis for the understanding of the metaphorical expressions. The person is moved by the external force along a path that has a starting point, a direction and a destination.

\subsection{EMOTION IS INSANITY}

This metaphor applies to very intense emotions such as anger, fear or love (Lakoff 1987; Kövecses 2000). The behaviour of the person affected by these emotions is usually very similar to the behaviour of an insane person. Insanity is the ultimate lack of control. The rational Self loses all control as a result of an intense psychological force and becomes completely irrational. The PATH and the COMPULSION schemas seem to interact in the sentences "She drove him berserk," and "He's gone mad over her". Both of them are examples of the conceptual metaphor EMOTIONAL CHANGE IS MOVEMENT FROM ONE LOCATION TO ANOTHER (Lakoff 1993), that is, the person changes from a normality state to another state of abnormality. The predicative expressions "She's nuts about him," "She is insane with fear," "I'm crazy about her," indicate that the emotional change has taken place and the person is in another location, experiencing the state of lack of emotional control. 


\subsection{EMOTION IS INTOXICATION}

The conceptualization of emotion as intoxication is also characterized by lack of control and passivity as a result of an emotional cause. Emotion plays an active role, while the person affected by the emotion loses his common sense and becomes dominated by the emotion: "He is intoxicated with love," "I am giddy with love," "She was drunk with emotion". "Emotion is viewed as some kind of alcoholic beverage capable of affecting a person's intellectual abilities in adverse ways" (Kövecses 2000:74). The metaphor captures the idea of the inability to speak and think.

\section{THE VERTICAL MODEL}

\subsection{EMOTIONS ARE SOCIAL SUPERIORS}

Emotions can also be viewed as social forces (Kövecses 2000: 70). In this metaphor we have two forces: the superior that is the emotion and the inferior that corresponds to the person. There is no struggle between both forces because the person is completely dominated by the emotion that controls him: "His emotions dominate his actions," "She is ruled by her emotions," "She is driven by fear". These expresions are also examples of the conceptual metaphor CONTROL IS UP AND LACK OF CONTROL IS DOWN (Lakoff \& Johnson 1980). "This metaphor primarily applies to a person whose behaviour is controlled by emotion, not by reason... A superior has long-term control over an inferior, whose behavior is determined by the superior over a long period of time" (Kövecses 2000: 71)

\subsection{SELF-CONTROL IS BEING ON THE GROUND}

This metaphor is a consequence of the general metaphor: EMOTIONAL STABILITY IS BALANCE (Lakoff 1993). Being in contact with the ground is being in control over our emotions, while being off our normal location on the ground is lack of control (Lakoff 1999: 275): "He's got his feet on the ground," "I'm on cloud nine," "She jumped for joy". HAVING CONTROL OVER EMOTIONS IS KEEPING THE EMOTIONS BELOW: "He couldn't rise above his emotions". THE LOSS OF THE EMOTIONAL CONTROL IS THE LOSS OF VERTICALITY: "They fell about laughing," "They all rolled around laughing".

\section{THE TEMPERATURE MODEL}

The common experience of gaining control over our emotions can be felt and conceptualized as reducing the temperature: "Keep cool," "Chill out," "He 
has cooled off now," "He has cooled down". These are metaphorical expressions of the metaphorical model of REDUCING EMOTIONAL INTENSITY IS REDUCING TEMPERATURE. We can adjust our emotions like a thermostat by adjusting the level on the heat scale: "Cool down a bit," "Don't get so hot under the collar. Thus, ADJUSTING EMOTIONAL CONTROL IS ADJUSTING A THERMOSTAT. When we are emotionally too hot in overarousal states like anger or anxiety we can turn down the thermostat to gain peace and calmness. When we are emotionally too cold in underarousal states like boredom and depression we can turn up the heat to get more energy and enthusiasm.

\section{THE ONTOLOGY AND PHENOMENOLOGY OF ONE EMOTIVE EXPRESSION: A DESCRITIVE ANALYSIS}

We propose here a model of description of emotive expressions. The symbolic construction of an emotive event can be analysed semantically by unveiling its different levels of representation: the extensional/propositional, intensional, phenomenological and cultural levels. In order to unpack the different types of semantic information, we present below one linguistic expression and analyse four models of meaning representation (Martín Morillas, J.M. \& Pérez Rull, J.C. 1998). Consider the following expression:

1. The little girl couldn't hold back her tears of joy

We propose here the following models, each of which is in charge of capturing a determinate type of meaning:

\section{EXTENSIONALIST/PROPOSITIONAL MODEL}

The linguistic expression incorporates a level of extensional meaning which represents the conceptual elements of the emotive event with the participants and circumstances. Given that the extensional level represents the objectivist aspects of meaning representation, it is possible to label objectively the propositional-ontological elements of the emotive experience by the following variables:

W: represents the stimulus of the emotive event which is unknown

$\mathrm{X}$ : refers to the person affected by the emotion: the little girl

Y: refers to the type of emotive experience: joy

$\mathrm{Z}$ : refers to the physiological effect that goes together with the emotion: tears 
Thus, the linguistic expression categorizes an unknown cause (W) that causes the emotive experience $(\mathrm{Y})$ of the person $(\mathrm{X})$ and the physiological manifestation of the emotion $(\mathrm{Z})$. This propositional model is based on the objectivist model offered by R. Buck (1986: 297)

\section{INTENSIONALIST MODEL}

This model emphasizes the internal semantic relations of lexical items, namely the relationships among signs to refer to the phenomenological experience. Our sentence codifies directly both the emotive experience: JOY $\rightarrow$ [HAPPINESS: to a high degree] and the physiological effect: TEARS. This level of meaning representation only pays attention to the systematic sense relations operating within a given lexical field and ignores the great variety of linguistic expressions such as figurative expressions, idioms, proverbs that encode the emotive experience and the cognitive and cultural models underlying the linguistic expressions. Therefore a different level of semantic representation seems to be needed: the motivational level, the cognitive and cultural level.

\section{PHENOMENOLOGICAL MODEL}

At this level we take into account the phenomenological aspect of meaning. Therefore we are concerned here with the mental models underlying the symbolic construction of the emotive experience that reports the loss of control over the emotion. It captures the relation of language to mind and the subject's own experience. The schemas of the force and counterforce underlie the linguistic codification that corresponds to the stage of loss of control of the prototypical scenario. The underlying conceptual model is EMOTIONS ARE ENEMIES. The emotion is seen as an enemy with whom we have to fight in order to keep him under control.

\section{CULTURAL MODEL}

This model emphasizes the relevant aspects of the intersubjective experience. The emotive expression seems to convey the cultural model that emotions should be regulated and controlled.

\section{CONCLUSION}

Emotions are internal and formless. Through metaphor we give emotions cognitive shape and make visible what seems amorphous. We also structure emotion concepts by means of a scenario in which the emotion metaphors converge. Emotional control has been conceptualized in terms of a variety of 
metaphors corresponding to the control stage of the five-stage cognitive model: a) emotion has a cause, b) the cause produces the emotion which forces us to respond, d) we try to control the emotion but we usually fail, and e) there is a response.

Metaphors play a significant role in structuring our experience. We control and lose control over emotions in the same way we control and lose control over certain physical forces. Conceptual metaphors allow mental imagery from sensorimotor domains such as fluids under pressure, captive animals, opponents or enemies, etc., to be used for the domain of our subjective experience about how we control and lose control over our emotions.

\section{REFERENCES}

Barcelona Sánchez, A. 1986. "On the Concept of Depression in American English: A Cognitive Approach". Revista Canaria de Estudios Ingleses 12: 7-35.

Buck, R. 1986. "The Psycho-Biology of Emotion". Mind and Brain. Dialogues in Cognitive Neuroscience. Eds. J.E. LeDoux and W. Hirst. Cambridge. Mass: Cambridge University Press. 275-300.

Johnson, M. 1987. The Body in the Mind: The Bodily Basis of Meaning, Reason and Imagination. Chicago: The University of Chicago Press.

Kövecses, Z. 1986. Metaphors of Anger, Pride, and Love. Amsterdam/Philadelfia: John Benjamins Publishing Company.

Kövecses, Z. 1990. Emotion Concepts. Berlin: Springer.Verlag

Kövecses, Z. 2000. Metaphor and Emotion: Language, Culture, and Body in Human Feeling. Cambridge: Cambridge University Press

Lakoff, G. \& Johnson, M. 1980. Metaphors We Live By. Chicago: University of Chicago Press.

Lakoff, G. 1987. Women, Fire, and Dangerous Things: What Categories Reveal about the Mind. Chicago: University of Chicago Press.

Lakoff, G. 1993. "The Contemporary Theory of Metaphor". Metaphor and Thought. Ed. A. Ortony. Cambridge: Cambridge University Press.

Lakoff, G. 1992. "Multiple Selves: The Metaphorical Models of the Self Inherent in Our Conceptual System". A Conference of the Mellon Colloquium on the Self at the Emory Cognition Project Emory University Atlanta, Georgia May 1-2,1992.

Lakoff, G. 1999. Philosophy in the Flesh: The Embodied Mind and Its Challenge to Western Thought. Basic books: New York

Martín Morillas J. M. 2000. "The Concept of Self: Some Cognitive-Cultural Considerations Concerning Its Categorization and Expression in Spanish". Language Design, n. 2. 
Martín Morillas J. M. \& Pérez Rull, J. C. 1998. Semántica Cognitiva Intercultural. Granada: Método Ediciones.

Peña Cervel, M. S. 1998. "The Role of the Control ICM and of Image Schemas in Metaphors for Understanding Emotions". The Pragmatics of Understanding and Misunderstanding. Universidad de Zaragoza. 